\title{
Firmaların Sermaye Yapısı Kararları, Kredi Risk Düzeyleri ve Karlılık Oranları Arasındaki İlişkinin Analizi: Panel Veri Analizi*
}

\author{
Füsun KÜÇÜKBAY ${ }^{1}$ Begüm GÜLER ${ }^{2}$ \\ Özet
}

Sermaye yapısı kararları ve firma karlılı̆̆ı arasındaki ilişki üzerine yapılan çalışmalarda tartışmalar hala devam etmektedir. Bu çalışmanın da başlangıç noktasını bu tartışmalar oluşturmuştur. Bu çalışmanın amacı sermaye yapısı kararlarının ve firmaların kredi risk düzeylerinin firma karlılığı üzerine etkisi olup olmadığını araştırmaktır. Çalışmada sermaye yapısı, kredi risk düzeyi ve firma karlılığı arasındaki ilişki panel veri analizi yardımı ile değerlendirilmiştir. Firma karlılı̆̆ını ölçmek için aktif karlılı̆̆ı oranı seçilmiştir (AK). Sermaye yapısını değerlendirebilmek için kaldıraç oranı ve uzun vadeli borç oranı seçilmiştir. Ayrıca firmaların kredi risklerini değerlendirmek için kukla değişken kullanılmıştır. Firma büyüklügünün de firma karlılığını etkilediği düşünülerek firma büyüklüğü de kontrol değişkeni olarak seçilmiştir. Çalışma da 2013-2017 yılları arasında Türkiye'de faaliyet gösteren 235 halka açık işletme çalışmanın örneklemini oluşturmuştur. Çalışma sonucunda sermaye yapısı kararlarından kaldıraç oranının firma karlılığını istatistiki olarak negatif yönde etkilediği bulunmuştur. Firma karlılığı ve firma büyüklüğü arasında da istatistiki olarak anlamlı pozitif bir ilişki olduğu tespit edilmiştir. Son olarak firmaların kredi risk düzeylerinin sermaye yapısı ve karlılık arasındaki ilişkide bir farklılık yaratmadı̆̆ı sonucuna ulaşılmıştır.

Anahtar kelimeler: Sermaye yapısı kararları, Karlılık, Panel veri analizi, kredi risk seviyesi

Jel Kodu: G32, L25

\section{The Analysis of The Relationship Between Capital Structure Decisions, Credit Risk Level and Profitability Ratios of Companies: Panel Data Analysıs}

\begin{abstract}
There is different studies about the relationship between the capital structure decisions and firms' profitability in literature and the debate about this matter still continues. The beginning point of this study is this debate. In the study it is aimed to examine if the decisions about the capital structure and the credit risk level of the firms influence the firms' profitability. In order to examine whether the capital structure decisions and credit risk level have an effect on the firms' profitability, a panel data analysis method have been used. In order to analyze the profitability, return on assets (ROA) ratio is selected. For analyzing the capital structure, leverage ratio and long-term debt ratio are used. Additionally a dummy variable is used in order to evaluate the credit risk level of the firms. It is thought that the size of the company has an effect on the profitability so the firm size is selected as the control variable. 235 publicly held companies operating in Turkey for 2013-2017 period, are selected as the sample of the study. . As a result of the study, it is found that the debt ratio has a statistically significant negative effect on the profitability of the firms. Also, it is found that there is a statistically significant positive relationship between firm size and firm profitability. Finally, it is concluded that the credit risk level of the firms does not make a difference on the relationship between capital structure and profitability.
\end{abstract}

Keywords: Capital structure decisions, profitability, panel data analysis, credit risk level

Jel Codes: G32, L25

\footnotetext{
* Bu makalede bilimsel araştırma ve yayın etiği ilkelerine uyulmuştur. / In this article, the principles of scientific research and publication ethics were followed.

Bu çalışma 1. Ktirik Araștırmalar Kongresinde bildiri olarak sunulmuştur.

ATIF ÖNERÍsí (APA): Küçükbay, F., Güler, B. (2020). Firmaların Sermaye Yapısı Kararları, Kredi Risk Düzeyleri ve Karlılık Oranları Arasındaki İlişkinin Analizi: Panel Veri Analizi. İzmir İktisat Dergisi. 35(1). 19-31. Doi: 10.24988/ije.202035102

${ }^{1}$ Doç. Dr., Manisa Celâl Bayar Üniversitesi, İşletme Fakültesi, Ekonomi ve Finans Bölümü, Finansman Anabilim Dalı, Manisa EMAIL: fusun.kucukbay@cbu.edu.tr ORCID: 0000-0001-6593-5884

2 Yüksek Lisans, Manisa Celal Bayar Üniversitesi, Sosyal Bilimler Enstitüsü, Muhasebe ve Finansman Yüksek Lisans, Manisa EMAIL: gulerbegum@hotmail.com ORCID: 0000-0003-1502-8236
} 


\section{GíRİS}

Firmaların temel amacı firma piyasa değerini en yükseğe taşımaktır. Firma piyasa değerini etkileyen kararlardan birisi de sermaye yapısı kararlarıdır. Sermaye yapısı kararları, varlıkların finansmanında kullanılan kaynaklar arasında seçim yapmayı içermektedir.

Günümüzde firmaların finansman sağlayabileceği seçenekler artmaktadır. İşletmelerin bu finansman seçeneklerinden firma için en iyi olanı bulması firmanın başarısı için çok önemlidir. $\mathrm{Bu}$ nedenle sermaye yapısı kararları finans alanında her zaman önemini korumaktadır.

$\mathrm{Bu}$ çalışma da sermaye yapısı kararlarının firma karlılığını etkileyip etkilemediği ve eğer etkiliyorsa ne yönde etkilediği araştırılmaya çalışılmıştır. Çalışmanın örneklemini Türkiye'de halka açlk 235 firma oluşturmaktadır. Diğer çalışmalardan farklı olarak, bu çalışmada sermaye yapısı kararlarının firma karlılığı üzerine etkisini araştırmak için geniş bir örneklem kullanılmıştır. Bu durum çalışmanın uygulama sonuçlarını zenginleştirmektedir. Ayrıca çalışma daha önce yapılan çalışmalara katkı olarak kredi risk düzeyinin sermaye yapısı ve firma karlılığı arasındaki ilişkiyi etkileyip etkilemediği incelenmiştir. Türkiye örnekleminde bu etkinin incelenmesi ilk defa gerçekleştirilmektedir. Yabancı literatürde de bilindiği kadarı kredi riski etkisinin incelendiği Li K. vd (2019) tarafından yapılan bir çalışma mevcuttur.

Çalışmanın ikinci bölümünde sermaye yapısı kavramı açıklanmış daha sonra sermaye yapısı ve karlılık ilişkisi ile ilgili daha önce yapılan çalışmalara yer verilmiştir. Dördüncü bölümde çalışmanın uygulama kısmında kullanılan değişkenler ve uygulamada kullanılan yöntem açıklanmış ve uygulama sonucunda elde edilen bulgulara yer verilmiştir. Son bölümde çalışmanın sonuçları değerlendirilmiş ve yorumlanmıştır.

\section{SERMAYE YAPISI KAVRAMI}

Sermaye yapısı, firma finansmanında kullanılan uzun vadeli borç ve özsermaye birleşimi şeklinde tanımlanabilir (Sayılgan, 2017: 325). Sermaye yapısı bize firmaların varlıklarını finanse etmek için ihtiyaç duyduğu fonları hangi kaynaktan ve ne kadar kullandığını göstermektedir. $\mathrm{Bu}$ kavramın önemli olmasının temel sebebi, firmaların sermaye yapısı kararlarını alırken, seçenek farklılıklarından dolayı oluşan maliyet ve riski iyi dengeleyebilmeleri durumunda piyasadaki diğer şirketlere göre daha avantajlı olabilmeleridir.

Fonların temini için firmaların iki seçeneği vardır; ya firma mevcut ve potansiyel yatırımclardan öz sermaye şeklinde fon bulacak ya da firma yabancl kaynak kullanacaktır. Öz sermayeden sağlanan fon ile yabancı kaynak şeklinde sağlanan fonların maliyetleri aynı değildir. Ortaklar borç verenlere göre daha fazla risk almaktadır bu nedenle ortaklar daha fazla getiri beklentisine sahiptir. Ayrıca ortaklara verilen kar payları, borçlara ödenen faiz gibi kardan düşülemez. Vergi faktörü borç maliyetinde avantaj sağlamaktadır. Bu etkenlerin sonucu olarak öz sermaye maliyeti borç maliyetine göre daha yüksektir ancak geri ödeme zorunluluğu mevcut olmadığı için yabancı kaynağa göre risk düzeyi daha düşüktür.

Yabancı kaynak kullanımında vade seçeneği de sermaye maliyetinde farklılıklara yol açmaktadır. Örneğin; kısa vadeli borçlanma uzun vadeli borçlanmaya göre genellikle daha risklidir çünkü kısa vadeli borçların artması, vadenin kısa olmasından dolayı firmanın nakit sıkıntısı yașamasına neden olabilmektedir. Uzun vadeli borçlanmada ise, borçların süresi uzun olduğu için firmanın nakit riski azalmaktadır. Ancak çoğunlukla uzun vadeli borçlar kısa vadeli borçlara göre daha yüksek maliyetlidir.

Sermaye yapısında farklı seçeneklerin farklı avantaj ve dezavantajlara sahip olması nedeni ile: 'firma, sermaye yapısını hangi kaynakların 
birleşiminden oluşturacaktır?' sorusunu cevaplamak güçtür.

Sermaye yapısı kararları firmanın sermaye maliyetine doğrudan etki etmektedir. Kısa vadeli kaynaklar, uzun vadeli kaynaklara göre genellikle daha ucuzdur çünkü ödeme yapllacak süre daha öngörülebilirdir. Uzun vadeli finansman da ise vade uzunluğu nedeni ile ortaya çıkan belirsizliklerden dolayı, uzun vadeli borçlanma kısa vadeli borçlanmaya göre genellikle daha yüksek maliyetlidir. $\mathrm{Bu}$ nedenlerden dolayı firmalar uzun vadeli yabancı kaynak ve öz sermaye kalemlerinin oranlarını değiștirerek firma sermaye maliyetini değiștirebilir.

Sermaye yapısı kararlarında amaç sermaye yapısı maliyetini en aza indirmek ve piyasa değerini en yükseğe çlkarmaktır. Ancak optimal sermaye yapısı hakkında çeşitli görüşler ortaya atılmasına rağmen; tam bir fikir birliğine ulaşılamamıştır. Sermaye yapısı için ortaya atılan birçok teori vardır ve aşağıda kısaca bunlara değinilmiştir;

Net Gelir Yaklaşımı; sermaye yapısını değiştirerek sermaye maliyetinin değişebileceğini, bu şekilde firma piyasa değerinin etkilenebileceğini savunur. Sermaye yapısını oluştururken yabancı kaynakların ağırlıklı olduğu sermaye yapısının tercih edilmesi gerektiğini savunmaktadır (Durand, 1952: 215-262).

Net Faaliyet Geliri Yaklaşımı; sermaye yapısındaki değişikliklerin, firmanın sermaye maliyetine ve firmanın değerine etkisi olmayacağı savunmaktadır. $\mathrm{Bu}$ yaklaşımda yabancı kaynak kullanımının artması durumunda riskin artacağl, bununla beraber ortakların istedikleri getirinin de artacağ ifade edilmektedir. $\mathrm{Bu}$ nedenle optimum sermaye maliyetinin olmadığı ve sermaye yapısı değişimlerinde ortalama sermaye maliyetinin sabit kalacağı savunulmaktadır (Durand, 1952: 215-262).

Geleneksel Yaklaşım; optimal bir sermaye yapısına ulaşılabileceğini savunmaktadır. Firma belirli bir yere kadar borçlanarak öz sermayeye göre daha az maliyetli sermaye yapısı oluşturabilecektir. Ancak; optimum noktadan sonra ise borçlanmak finansal riski arttıracağı için optimal sermaye maliyetinden uzaklaşmaya başlanılacaktır. Bu optimal nokta sonrasında borçlanmayı arttırmaya devam eden firmaların ağırlıklı ortalama sermaye maliyeti artacak ve firma değeri düşecektir (Sayllgan, 2017: 336).

Modigliani-Miller ilerleyen dönemde optimal sermaye yapısı için farklı bir yaklaşım geliştirmiştir. Modigliani-Miller yaklaşımında; net faaliyet geliri yaklaşımına benzer olarak, sermaye yapısındaki değișimlerin sermaye maliyetini etkilemeyeceği savunulur. $\mathrm{Bu}$ görüşte piyasalarda arbitraj nedeni ile fiyat farkının ortadan kalkacağı ve sermaye maliyetinin aynı kalacağı savunulmaktadır (Sayllgan, 2017: 539). Modigliani ve Miller'ın geliştirdikleri teoride yer alan varsayımlar normal piyasa şartlarından oldukça uzaktadır. Özellikle teoride vergileri ele almamaları eksiklik olarak görülmüştür. Çünkü firmalar da yatırımcılar da vergi ödemektedir ve vergi yatırım kararlarında etkili bir faktördür (Modigliani ve Miller, 1958: 261-297). 1958 yılında yayınladıkları makalede kurumlar vergisi modelde yer almamıştır, ancak 1963 yılındaki geliştirdikleri modelde kurumlar vergisi dahil edilmiştir (Modigliani vd., 1963: 433-443). Yabancl kaynak kullanımında ödenen faizler vergiden düşülerek yabancı kaynak maliyeti azaltılmaktadır. Bu terim literatüre 'vergi kalkanı' olarak geçmiştir. Vergi etkisi ile birlikte sermaye maliyeti biraz daha düşmektedir. 1977 yılına gelindiğinde Miller kurumlar vergisini dikkate alan modele, kişilerin sermaye kazançları üzerinden ödedikleri gelir vergisini dahil ettiği bir model daha ortaya koymuştur (Miller, 1977: 261275). Çalışmanın sonucu olarak Miller, sadece kurumlar vergisinin etkisinin olmadığını yatırımcıların ödediği gelir vergisinin de sermaye yapısı kararlarına etkisi olduğunu saptamıștır. Bunun temel sebebi yatırımcıların verdiği borca karşılık elde ettikleri faiz gelirleri bir kez vergilendirilmektedir. Ancak elde edilen kâr 


\section{F. KÜÇÜKBAY - B. GÜLER}

payı için hem şirket vergi vermektedir hem de ortaklar bireysel olarak gelir vergisi ödemektedir.

Modigliani ve Miller'in modelinin geliștirilmesinden sonra ilerleyen dönemlerde diğer araştırmacılar sermaye yapısını etkileyen farklı değişkenleri ele alarak farklı teoriler geliştirmişlerdir. Yapılan çalışmalar modern teoriler olarak adlandırılmıştır. $\mathrm{Bu}$ teorilere de aşağıda kısaca değinilmiştir;

Ödünleşme teorisine göre, borçlanma düzeyindeki artış, iflas ve temsilcilik maliyetlerini arttırmakta, bu da firma değerini azaltmaktadır (Gülşen ve Ülkütaş, 2012: 4959). Teoriye göre optimal sermaye maliyeti için; faizin vergi tasarrufu ile finansal sıkıntı maliyeti arasındaki optimal düzey belirlenmeli ve sermaye yapısı buna göre şekillenmelidir görüşü benimsenmiştir.

Sinyal teorisinin temelinde firma yöneticilerinin, piyasa algıları üzerinde yaptıkları değişiklikler vardır. Yöneticiler, dıș çevreye gönderdikleri ufak mesajlar ile oluşan piyasa algılarını manipüle ederek firma değerinde değișiklikler yaratmaya çalıșırlar. Örneğin; yabancı kaynak kullanarak fon sağlamanın firmanın piyasa algısı üzerinde pozitif etkisi olacağı ve doğru orantılı olarak firma değerine de pozitif etkisi olacağını düșünülmektedir. Bunun yanında firmanın hisse senedi ihraç etmesinin negatif bir sinyal verdiği düşünülmektedir (Myers ve Majluf, 1984: 187-221).

Temsil teorisi günümüzde oldukça popüler hale gelmiştir. Bu teoride firma yetki devri ile beraber yöneticiye karar alma konusunda büyük sorumluluklar verilmektedir. Ancak zamanla yöneticiler daha fazla kazanma amacı ile firmanın menfaatlerinden çok kendi başarılarına odaklanarak gereksiz borçlanma yapabilir, pahalı borçlanabilir ya da firma menfaatlerine uygun olmayan herhangi bir davranış sergileyebilirler. Yöneticilerin kendi çıkarlarına daha fazla önem vermesi, firmaların sermaye yapısında değişiklik olmasina neden olabilmektedir (Jensen ve Meckling, 1976: 305-360).
Diğer önemli teorilerden biri de finansman hiyerarşisidir. Finansman hiyerarşisi teorisine göre firmaların temel finansman kaynakları içsel finansman kaynakları ve dişsal finansman kaynakları olmak üzere ikiye ayrılmaktadır. Firmalar öncelikle finansman kaynağı olarak içsel finansman kaynaklarını, daha sonrasında dişsal finansman kaynaklarını kullanmaktadırlar. Bu teori; kar elde eden firmaların dış kaynaklardan fon sağlamak yerine iç kaynaklardan fon sağladığını öne sürmektedir (Myer ve Majluf, 1984: 187-221).

Sermaye yapısı hakkındaki tüm teoriler birbiri ile ilișki içerisindedir. Bir teori diğerinin eksikliklerinden ortaya çıkmış, onu tamamlar niteliktedir. Bundan dolayı teoriler birbirinden tam anlamiyla ayrı değildir. Günümüzde de 'sermaye yapısı teorileri' hala gelişimini sürdürmektedir.

\section{SERMAYE YAPISI VE KARLILIK İLIŞKISI}

Modigliani ve Miller'ın yaptıkları ilk çalışmanın dayandığı varsayımlar gerçek dünyada olamayacak kadar mükemmeldir (Modigliani ve Miller, 1958: 261-297). Bu nedenle ilk yaptıkları çalışmada firmanın borç/özsermaye oranının firma değerinin üzerinde etkisinin olmadığını savunmuşlardır. Ancak, daha sonra eklenen vergi etkisi ile birlikte sermaye yapısı kararlarının firma performansı üzerinde etkili olduğunu görmüşlerdir (Modigliani ve Miller, 1963:43343). Yapılan çalışmalarda firmaların daha fazla borç kullanması durumunda firma değerinin artabileceği fikri savunulmuştur. Bos ve Fetherston'un 1993 yılındaki yayınlanan eserlerinde de sermaye yapısındaki değişikliklerin firma karlılığı ve riskini etkilediği tespit edilmiștir (Bos ve Fetherston, 1993: 53-66).

Tablo 1'de sermaye yapısı ve firma karlılığı ilişkisi üzerine yapılan çalışmalar özetlenmiştir. 
Tablo.1 Literatür Özeti

\begin{tabular}{|c|c|c|c|c|c|}
\hline YAZAR & YIL & ÜLKE & DEĞİŞKENLER & YÖNTEM & SONUÇLAR \\
\hline Abor & 2005 & Gana & 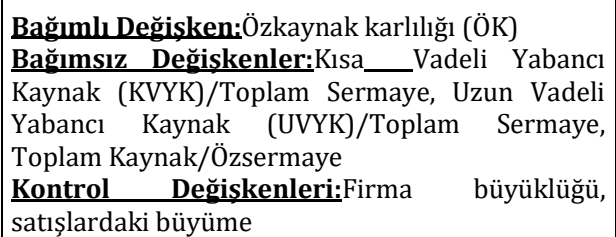 & Regresyon Analizi & $\begin{array}{l}\text { Karlılık oranları ve kaldıraç } \\
\text { oranları arasında negatif bir } \\
\text { ilişki bulunmuştur }\end{array}$ \\
\hline Kabakçı & 2008 & Türkiye & $\begin{array}{l}\text { Bağımlı Değişken:ÖK } \\
\text { Bağımsız Değiskenler: KVYK/ Toplam kaynaklar, } \\
\text { UVYK/ Toplam kaynaklar, Toplam borç/Toplam } \\
\text { kaynaklar, Toplam Borç/özsermaye } \\
\text { Kontrol Değisskenleri:Firma büyüklüğü, Büyüme } \\
\text { oranı Borç dışı vergi kalkanı, Vergi oranı }\end{array}$ & \begin{tabular}{|l|} 
\\
Genelleştirilmiş \\
En Küçük Kareler
\end{tabular} & $\begin{array}{l}\text { Özsermaye karlılığı ve borç } \\
\text { oranı arasında negatif bir ilişki } \\
\text { saptanmıştır. Düşük borç } \\
\text { oranının yüksek karlılığa } \\
\text { ulaşmada etkili } \quad \text { olduğu } \\
\text { görülmüștür. }\end{array}$ \\
\hline $\begin{array}{l}\text { Azhagaiah, } \\
\text { Gavoury }\end{array}$ & 2011 & Hindistan & $\begin{array}{l}\text { Bağımlı Değişkenler:ÖK, Kullanılan sermayenin } \\
\text { getirisi } \\
\text { Bağımsız Değişkenler: Toplam Borç/Toplam } \\
\text { Kaynak, Toplam Borç/Özsermaye oranı, Cari oran }\end{array}$ & Regresyon Analizi & $\begin{array}{lrr}\text { Karlılık } & \text { değişkenleri } \\
\text { sermaye } & \text { yapısı değişkenleri } \\
\text { arasında bire bir } & \text { ilişsi vardır. } \\
\text { Sermaye yapısı } & \text { karlılık } \\
\text { üzerinde } & \text { etkilidir } & \text { sonucuna } \\
\text { ulașılmıștır. } & \end{array}$ \\
\hline $\begin{array}{l}\text { Gill, Biger } \\
\text { and Mathur }\end{array}$ & 2011 & Kanada & $\begin{array}{l}\text { Bağımlı Değișkenler:ÖK } \\
\text { Bağımsız Değișkenler: KVYK/Toplam Kaynaklar, } \\
\text { UVYK/Toplam Kaynaklar, Toplam Borç/toplam } \\
\text { varlıklar } \\
\text { Kontrol Değişkenleri: firma büyüklüğü, satış } \\
\text { büyümesi, ve sektör }\end{array}$ & $\begin{array}{l}\text { Kolerasyon ve } \\
\text { Regresyon Analizi }\end{array}$ & $\begin{array}{l}\text { KVYK/Toplam } r \text { Kaynak, } \\
\text { UVYK/Toplam Kaynak, Toplam } \\
\text { Borç/Toplam Kaynak ve ÖK } \\
\text { arasında pozitif ilişki } \\
\text { saptanmıştır. }\end{array}$ \\
\hline Yakar & 2011 & Türkiye & $\begin{array}{l}\text { Bağımlı Değiskenler:Net Kar/ Toplam aktif, } \\
\text { Bağımsız Değişkenler:Toplam Borç/Özsermaye, } \\
\text { KVYK/Özsermaye, UVYK/Özsermaye }\end{array}$ & Panel Veri Analizi & $\begin{array}{l}\text { Sermaye yapısını ifade eden } \\
\text { bağımsız değişkenler ve karlıllık } \\
\text { arasında negatif yönlü bir ilişki } \\
\text { olduğu bulunmuștur. }\end{array}$ \\
\hline $\begin{array}{l}\text { Karadeniz, } \\
\text { Atioğlu ve } \\
\text { İskenderoğlu }\end{array}$ & 2012 & Türkiye & $\begin{array}{l}\text { Bağımlı Değişkenler: ÖK, AK } \\
\text { Bağımsız Değiskenler: Bir önceki yılı̈ ÖK'si, Bir } \\
\text { önceki yılın AK'sı, Mevduat/ Özkaynaklar, } \\
\text { Mevduat/ Toplam Aktif }\end{array}$ & $\begin{array}{l}\text { Genişletilmiş } \\
\text { Momentler } \\
\text { Metodu }\end{array}$ & $\begin{array}{l}\text { Sermaye yapısı ile banka } \\
\text { karlıllğı arasında negatif ilişski } \\
\text { bulunmuştur. }\end{array}$ \\
\hline $\begin{array}{l}\text { Shubita, } \\
\text { Alsawalhah }\end{array}$ & 2012 & Ürdün & 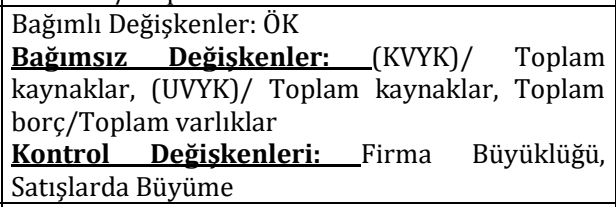 & $\begin{array}{l}\text { Kolerasyon ve } \\
\text { Çoklu Regresyon } \\
\text { Analizi }\end{array}$ & $\begin{array}{ll}\text { Borç oranının } & \text { artmasının } \\
\text { karlılığı } & \text { düşürdüğü } \\
\text { bulunmuştur. } & \end{array}$ \\
\hline Rahimi vd. & 2013 & İran & $\begin{array}{l}\text { Bağımlı Değişkenler: Net kar marjı, ÖK, AK } \\
\text { Bağımsız Değișkenler; Toplam borç/Toplam } \\
\text { varlık, KVYK/ Toplam Kaynak, UVYK/ Toplam } \\
\text { kaynak } \\
\text { Kontrol değişkeni; Şirket büyüklüğü }\end{array}$ & Regresyon Analizi & $\begin{array}{l}\text { Karlılık oranları ve sermaye } \\
\text { yapısı değişkenleri arasında } \\
\text { negatif bir ilişki bulunmuştur. }\end{array}$ \\
\hline Doğan & 2013 & Türkiye & $\begin{array}{l}\text { Bağımlı Değişkenler:AK } \\
\text { Bağımsız Değișkenler:Aktif büyüklük, Likidite, } \\
\text { kaldıraç oranı, hasar primi oranı ve firma yaşı } \\
\text { kullanılmıştır. }\end{array}$ & \begin{tabular}{|lr} 
Çoklu & Regresyon \\
ve & Kolerasyon \\
Analizi &
\end{tabular} & \begin{tabular}{|lr} 
Aktif büyüklüğg̈ ve karlılık \\
arasında pozitif yönlü bir ilișki \\
olduğu tespit edilmiștir. \\
Kaldıraç oranı arttıkça \\
karlılığın azaldığı bulunmuștur.
\end{tabular} \\
\hline Hassan & 2015 & Türkiye & $\begin{array}{l}\text { Bağımlı Değişken:ÖK, } \mathrm{AK} \\
\text { Bağımsız Değiskenler: } \\
\text { UVYK/toplam kaynak }\end{array}$ & Panel Veri Analizi & $\begin{array}{l}\text { Özkaynak karlılığ ve kısa } \\
\text { vadeli borç oranı ve uzun } \\
\text { vadeli borç oranı arasında } \\
\text { negatif bir ilișki belirlenmiștir. }\end{array}$ \\
\hline $\begin{array}{l}\text { Lara, } \\
\text { Mesquita }\end{array}$ & 2015 & Brezilya & $\begin{array}{l}\text { Bağımlı Değişkenler: ÖK } \\
\text { Bağımsız Değișkenler:_UVYK/Toplam Kaynak, } \\
\text { Özsermaye/Toplam Kaynak, KVYK/ Toplam } \\
\text { Kaynak, UVYK/Özkaynak }\end{array}$ & En Küçük Kareler & $\begin{array}{l}\text { ÖK ile KVYK borç oranı ve } \\
\text { özkaynak oranı arasında pozitif } \\
\text { bir korelasyon vardır. }\end{array}$ \\
\hline Hamid vd. & 2015 & Malezya & 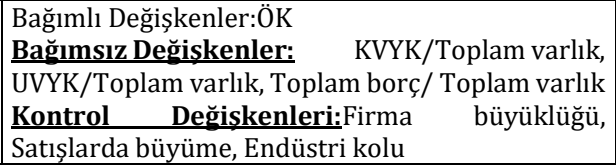 & Panel Veri Analizi & $\begin{array}{l}\text { Borçlanma oranlarının karlılık } \\
\text { ile negatif yönlü bir ilişki içinde } \\
\text { olduğu bulunmuştur. }\end{array}$ \\
\hline
\end{tabular}


Tablo.1 Literatür Özeti (Devamı)

\begin{tabular}{|c|c|c|c|c|c|}
\hline YAZAR & YIL & ÜLKE & DEĞİŞKENLER & YÖNTEM & SONUÇLAR \\
\hline $\begin{array}{l}\text { Kaplan, } \\
\text { Karadeniz, } \\
\text { Günay }\end{array}$ & 2016 & Türkiye & $\begin{array}{l}\text { Bağımlı Değişkenler: Net kar marjı, AK } \\
\text { Bağımsız Değişkenler: Kaldıraç oranı }\end{array}$ & Panel Veri Analizi & $\begin{array}{l}\text { Borçlanmanın artması karlılı̆ı negatif } \\
\text { etkiler. }\end{array}$ \\
\hline Akgüneş & 2017 & Türkiye & $\begin{array}{l}\text { Bağımlı Değișkenler: ÖK } \\
\text { Bağımsız Değiskenler: Özkaynak/Toplam } \\
\text { kaynak, UVYK/ Toplam kaynaklar, Toplam } \\
\text { borç/ Toplam varlık }\end{array}$ & Panel Veri Analizi & $\begin{array}{l}\text { Özkaynak/ Toplam Kaynak oranı ÖK'nı } \\
\text { negatif etkilediği, diğer değișkenlerin ÖK } \\
\text { üzerinde bir etkisi olmadığı } \\
\text { bulunmuștur }\end{array}$ \\
\hline Alsu & 2017 & Türkiye & $\begin{array}{l}\text { Bağımlı Değişkenler: AK } \\
\text { Bağımsız Değiskenler: Özkaynak/Toplam } \\
\text { Kaynaklar, UVYK/Toplam kaynaklar, Yasal } \\
\text { Yedekler/ Toplam Kaynaklar, Hisse senedi } \\
\text { toplamı/Toplam kaynak }\end{array}$ & Panel Veri Analizi & $\begin{array}{l}\text { Sermaye yapısında özkaynak kullanımı } \\
\text { artarsa firma karlılı̆ını pozitif etkiler, } \\
\text { borçların artması durumunda firmanın } \\
\text { karlılığı etkilenmez sonucuna } \\
\text { ulașılmıștır. }\end{array}$ \\
\hline Jouida & 2017 & Tunus & $\begin{array}{l}\text { Bağımlı Değişken: AK } \\
\text { Bağımsız Değişken: Kaldıraç oranı }\end{array}$ & \begin{tabular}{ll|} 
Panel Veri & Analizi \\
(Panel & Vektör \\
otoregresyon \\
modeli)
\end{tabular} & $\begin{array}{l}\text { Sermaye yapısı ve karlılı arasında ters } \\
\text { nedensellik vardır sonucu bulunmuștur. }\end{array}$ \\
\hline Le vd. & 2017 & Vietnam & $\begin{array}{l}\text { Bağımlı Değişken: AK, Tobin Q, ÖK } \\
\text { Bağımsız Değisken: Kaldıraç oranı, nakit } \\
\text { akışı, Likidite, kar payı dağıtımı }\end{array}$ & Panel Veri & $\begin{array}{l}\text { Borç oranları ile firma performansı } \\
\text { arasında negatif bir ilişsi bulunmuştur. }\end{array}$ \\
\hline $\begin{array}{l}\text { Andaleeb } \\
\text { vd. }\end{array}$ & 2018 & Pakistan & $\begin{array}{l}\text { Bağımlı Değişken: Kaldıraç oranı } \\
\text { Bağımsız Değişken: Likidite oranları, } \\
\text { karlılı oranları, toplam varlıklar, } \\
\text { yatırımlar/toplam varlıklar }\end{array}$ & Panel veri & $\begin{array}{l}\text { Sermaye yapısını en iyi açıklayan } \\
\text { değişken likidite } \\
\text { bulunmuştur. }\end{array}$ \\
\hline Li K. vd. & 2019 & $\begin{array}{l}\text { Avrupa } \\
\text { ülkeleri }\end{array}$ & $\begin{array}{l}\text { Bağımlı Değisken: Firma performansı } \\
\text { Bağımsız Değişken: Kaldıraç oranı, kredi } \\
\text { risk düzeyi }\end{array}$ & Panel veri Analizi & $\begin{array}{l}\text { Borçluluk oranı kredi riski } \text { yüksek } \\
\text { firmalarda performansı } \\
\text { etkilemektedir. Kredi riski düșük } \\
\text { firmalarda ise borçluluk oranı firma } \\
\text { performansını negatif etkilemektedir. }\end{array}$ \\
\hline Söylemez & 2019 & Türkiye & $\begin{array}{l}\text { Bağımlı Değişken: kaldıraç oranı } \\
\text { Bağımsız Değisken. borç dışı vergi kalkanı, } \\
\text { karlılık ve likidite oranları }\end{array}$ & Panel veri Analizi & $\begin{array}{l}\text { Kaldıraç oranları ile likidite ve büyüklük } \\
\text { değişkenleri arasında negatif iliş̧ki, borç } \\
\text { dışı vergi kalkanı ve karlılık değişkenleri } \\
\text { arasında ise pozitif ilișki vardır. }\end{array}$ \\
\hline
\end{tabular}

Çalışmalar incelendiğinde birçok yöntem kullanılmasına rağmen, genellikle panel veri analizi yöntemi tercih edildiği görülmektedir. Çalışmaların genelinde bağımlı değişken olarak aktif karlılığı (AK) ve özkaynak karlılığı (ÖK) oranları seçilmiştir. Bağımsız değişken olarak kısa vadeli yabancı kaynaklar/toplam kaynaklar, uzun vadeli yabancı kaynak/toplam kaynaklar, özkaynak/toplam kaynaklar ve toplam borç/toplam varlık (kaldıraç oranı) oranları tercih edilmiștir. Kontrol değişkeni olarak da şirket büyüklüğü kullanılmıștır. Literatür incelemesinde çoğunlukla gelişmekte olan ülkeler örneklemine ait çalışmalara yer verilmiştir. Çalışmaların sonuçları incelendiğinde sermaye yapısı kararlarının firmaların karlılığına etkisi olduğu sonucuna ulaşan çalışmaların büyük bir çoğunluğunda borç oranları ile firma karlılığı arasında negatif bir ilişki bulunmuştur.
Türkiye örneklemi dikkate alınarak yapılan çalıșmalarda firmaların kredi risk düzeyleri ve firmaların sermaye yapısı ve karlılık arasındaki ilişkinin incelenmesi yapılmamıştır. $\mathrm{Bu}$ çalışmada daha önce yapılan çalışmalara katkı olarak kredi risk düzeyinin sermaye yapısı ve firma karlılığı arasındaki ilişkiyi etkileyip etkilemediği incelenmiştir. Ayrıca sermaye yapısı kararları, kredi risk düzeyi ve karlılık arasındaki ilişkinin incelenmesi amacı ile geniş bir örneklem kullanılmıştır. Bu durum çalıșmanın uygulama sonuçlarını zenginleştirmektedir.

\section{UYGULAMA}

Çalışmanın temel amacı sermaye yapısı kararlarının firma karlılığına etkisi olup olmadığını ve firmaların kredi risk düzeyinin sermaye yapısı ve firma karlılığı arasındaki ilişkiyi etkileyip etkilemediğini araştırmaktır. $\mathrm{Bu}$ bölümde çalışmanın veri seti, çalışmada kullanılan model, çalışmanın yöntemi ve çalışma bulgularına yer verilmiştir. 


\subsection{Veri ve Örneklem Grubu}

Çalışmada 2013-2017 yılları arasında kesintisiz veriye sahip ve Borsa İstanbul'da işlem gören 235 firmanın finansal oranları kullanılmıştır. Firmalara ait veriler Thomson Reuters Eikon programından yararlanılarak toplanmıştır. Thomson Reuters Eikon veri tabanı hem içerik hem de doğruluk açısından genel kabul görmüş bir veri tabanıdır.

\subsection{Model ve Değişkenler}

Firmaların sermaye yapısının firmaların karlılığı üzerinde etkisi olup olmadığını ve kredi riskinin sermaye yapısı ve firma karlılığı ilişsisinde bir farklılık yaratıp yaratmadığını değerlendirebilmek amacı ile aşağıdaki regresyon modeli geliştirilmiştir.

$R O A_{i t}=\beta_{i}+\beta_{1}$ bor $_{\text {sit }}+\beta_{2}$ uzunvadel $_{i t}+\beta_{3} K_{i t}+\beta_{4} B_{i t}+e_{i t}{ }^{1}(1)$

Regresyon modelinde kullanılan değişkenler ve açılklamaları Tablo 2'de verilmiştir.

Çalışma da firma karlılığı bağımlı değişkendir. Firma karlılığını değerlendirmek amacı ile aktif karlılığı oranı seçilmiştir.

Tablo 2: Modeli Olușturan Değișkenler Listesi

\begin{tabular}{|c|c|c|}
\hline DEĞİŞKENLER & KOD & AÇIKLAMA \\
\hline $\begin{array}{c}\text { Bağımlı } \\
\text { Değişken }\end{array}$ & $\mathrm{AK}$ & $\begin{array}{l}\text { Aktif Kârlılık=Net Kâr/ } \\
\text { Toplam Varlıklar }\end{array}$ \\
\hline \multirow{4}{*}{$\begin{array}{c}\text { Bağımsız } \\
\text { Değişkenler }\end{array}$} & borç & $\begin{array}{l}\text { Borçluluk oranı: Toplam } \\
\text { Borç/Toplam Varlıklar } \\
\end{array}$ \\
\hline & uzunvadeli & $\begin{array}{l}\text { Uzun vadeli Borç Oranı } \\
(U V B)= \\
\text { Kaynaklar }\end{array}$ \\
\hline & K & $\begin{array}{l}\text { Kredi Riski: Kukla } \\
\text { Değișkeni } \text { (Borçluluk } \\
\text { Oranı \%50 nin üzerinde } \\
\text { olan firmalara '1' \%50 nin } \\
\text { altında olan firmalara '0' } \\
\text { verilmiștir) }\end{array}$ \\
\hline & B & $\begin{array}{l}\text { Büyüklük: } \\
\text { aktiflerin logaritması }\end{array}$ \\
\hline
\end{tabular}

Çalışmada üç tane bağımsız değișken kullanılmıştır. Bağımsız değişkenlerden biri borç oranı diğeri ise uzun vadeli borçların toplam kaynaklar içindeki payıdır. Üçüncü değișken firmaların kredi riskidir. Çalışma da ayrıca firma karlılığını etkilediği düşünülen firma büyüklügü kontrol değişken olarak seçilmiştir.

\subsection{Yöntem}

Bu çalışmada panel veri analiz yöntemi tercih edilmiştir. Bunun temel nedeni çalışmada hem firmalara ait verilerin hem de zaman serisi verilerinin mevcut olmasıdır. Çalışma da yatay kesiti 235 firmaya ait veriler oluşturmaktadır. Zaman kesiti ise 2013-2017 dönemini içermektedir. Panel veri analiz tekniği, birçok bağımsız değişkenin belirli bir bağımlı değişken üzerine etkisini de analiz etmeye olanak sağlayan bir yöntemdir. Panel veri analizi yalnızca zaman serisi analizi ya da yatay kesit analizi yapmak yerine hem yatay kesitin hem de dikey kesitin bir arada ele alınmasına imkan vermektedir.

Panel veri analiz yönteminde iki temel model kullanılmaktadır. $\mathrm{Bu}$ modeller sabit etkiler modeli ve tesadüfi etkiler modelidir. $\mathrm{Bu}$ modellere ait bilgiler aşağıda verilmiştir.

\section{Sabit Etkiler Modeli}

Sabit etki modelinin zaman içinde farklılık gösteren değişkenlerin etkisini değerlendirmek istediğiniz zaman kullanılması uygundur. Sabit etkiler modeli birimler içinde (within tahminleyici) ve sonuç değişkenleri arasındaki ilişkiyi incelemektedir. Her birim (ülke, firmalar, insanlar vb.) değişkenler üzerinde etkisi olabilen ya da olmayan kendine özgü özelliklere sahiptir. Sabit etkiler modeli kullanılırken birimlere ait özelliklerin değişkenleri etkileyebileceği varsayılmaktadır. Örneğin bir ülkenin politik yapısının ülke ticaretinde etkisi olabilir ya da bir firma uygulamalarının firmanın hisse fiyatlarına etkisi olabilir. Sabit etkiler modeli birimler içindeki değişimlerin nedenini açıklamada başarılıdır.

Sabit etki modelinde yatay kesit birimleri arasındaki farklılıklar, sabit terimdeki farklılıklarla açıklanmakta ve panel veri modeli kukla değișkenler kullanılarak tahmin edilmektedir. Bu modelde çok fazla sayıda kukla değişken kullanılması nedeniyle sabit etkiler modelinde serbestlik derecesi kaybı oluşabilmektedir.

Sabit etki modelinde $\mathrm{Y}$ bağıml değişken X bağımsız değişken $\mathrm{E} n$ adet birimi (kukla değişken), $\beta$ lar model katsayılarını, T zaman 


\section{F. KÜÇÜKBAY - B. GÜLER}

kukla değişkenini, $\delta 2$ zaman kukla değişkeninin katsayısını, $\gamma 2$ birim kukla değişkeninin katsayısını, uit hata terimini

ifade etmek üzere sabit etkiler modeli aşağıdaki şekilde ifade edilir.

$$
Y_{i t}=\beta_{0}+\beta_{1} X 1_{i t}+\cdots \beta_{k} X k_{i t}+\gamma_{2} E_{2}+\cdots \gamma_{n} E_{n}+\delta_{2} T_{2}+\cdots \delta_{t} T_{t}+u_{i t}
$$

Eşitlik (2)'deki “i” indisi birimleri (hane halkı, bireyler, firmalar vb), t zaman kesiti ifade etmektedir

\section{Tesadüfi Etkiler Modeli}

Sabit etkiler modelinde birey sayısının fazla olması durumunda serbestlik derecesi azalacaktır. Bunun yanında, sabit etkiler modeli kullanımı zamanla değişmeyen bazı değişkenlerin (Örneğin; cinsiyet) modelde yer almasını sağlayamamaktadır. Bu șekilde kukla değişkeninin de modele eklenmesi ile bu değişkenler dahil edilebilmektedir. Kukla değişkenler modeli açıklamada yetersiz kalıyorsa bu durumda 'rasssal etkiler modeli' kullanmak daha doğru olacaktır. Bu modelde sabit etkiler modelinin, model hakkında doğru bilgi vermediği durumda 'hata terimi' ni kullanarak ilişkiyi açıklamaya çalışmaktadır.

Tesadüfi etkiler modelinde, zamana bağlı meydana gelen değişiklikler ya da birimlerin kendisinden mevcut olan farklılıkları bir hata terimi bileşeni olarak modele eklenerek serbestlik derecesi kaybı önlenmeye çalışılmaktadır.

Tesadüfi etkiler modelinde birim etki $\left(\mu_{i}\right)$ tesadüfi olduğundan modele hata terimi eklenmektedir. $\mathrm{Bu}$ durum tesadüfi etkiler modelinde;

$Y_{i t}=X_{i t}^{\prime} \beta+\alpha+\left(u_{i t}+\mu_{i t}\right)$

şeklinde ifade edilmektedir.

Panel veri analizinde hata terimlerinin ardışık değerlerinin birbirinden bağımsız olduğu, hata terimlerinin varyanslarının normal dağıldığı ve ortalamasının sıfır olduğu kabul edilir. Panel veri analizini gerçekleştirmeden önce bu varsayımların geçerli olup olmadığını test etmek amacı ile değișen varyans, yatay kesit bağımlılığı ve otekorelasyon testlerinin gerçekleştirilmesi gerekir.
Çalışmada ilk olarak veri setinin panel veri analizine imkân verip vermediği kontrol edilmiştir. $\mathrm{Bu}$ amaçla veri setine $\mathrm{F}$ testi yapılmıştır.

F testinin sonuçları tablo 3'de görülmektedir. Tablo 3'de görüldüğü gibi veri setinin panel veri modeli için $\% 99$ güven düzeyinde uygun olduğu bulunmuştur.

Tablo 3. F Testi Sonuçları

\begin{tabular}{|l|l|l|l|l|}
\hline & $\begin{array}{l}\text { Gözlem } \\
\text { Sayısı }\end{array}$ & $\begin{array}{l}\text { Serbestlik } \\
\text { Derecesi }\end{array}$ & F değeri & P değeri \\
\hline Model & 1175 & $(3,937)$ & 8,88 & $\mathbf{0 , 0 0 0 0 *}$ \\
\hline
\end{tabular}

(Not: * işareti \%99 güven düzeyinde anlamlı olduğunu ifade etmektedir )

Panel veri analizi yöntemi kullanılırken en çok tercih edilen iki model tesadüfi etkiler modeli ve sabit etkiler modelidir. Çalışmanın hangi modelin daha uygun olduğunu belirlemek amacı ile formül (4) de eşitliği gösterilen Hausman test istatistiği kullanılmıştır. Hasuman test istatistiği p değeri kullanılarak değerlendirilmiștir. Hausman test istatistiğine ait değerler tablo 4'de verilmiştir.

$$
H=\left(\widehat{\boldsymbol{\beta}}^{R E}-\widehat{\boldsymbol{\beta}}^{S E}\right)^{\prime}\left[\operatorname{Var}\left(\widehat{\boldsymbol{\beta}}^{R E}\right)-\operatorname{Var}\left(\widehat{\boldsymbol{\beta}}^{S E}\right)\right]^{-1}\left(\widehat{\boldsymbol{\beta}}^{R E}-\widehat{\boldsymbol{\beta}}^{S E}\right)
$$

Sırasıyla sabit etkiler modeli ve tesadüfi etkiler modeli için $\hat{\beta}^{R E}$ ve $\hat{\beta}^{S E}$ tahminleycilerin katsayı vektörünü temsil etmektedir

\begin{tabular}{|c|c|c|c|}
\hline & $\begin{array}{l}\text { Sabit etkiler-Tesadüfi } \\
\text { etkiler Katsayı Farkı }\end{array}$ & $\begin{array}{lr}\text { Chi } & 2 \\
\text { Değeri }\end{array} \mid$ & $\begin{array}{l}\text { P } \\
\text { Değeri }\end{array}$ \\
\hline $\begin{array}{|ll|}\text { Hausman } & \text { Test } \\
\text { İstatistiği } & \\
\end{array}$ & 0.02379 & 11,56 & 0.0209 \\
\hline
\end{tabular}

Tablo 4. Hausman Test İstatistiği Sonuçları

Hausman test istatistiğinin sonucunda $p$ değeri 0.0209 çıkmıştır. Bu sonuca göre \%95 güven düzeyinde çalışmada verilerin sabit etkiler tahmincisi ile analiz edilmesi gerektiği bulunmuştur. 
Verilerin analizine başlamadan önce değișen varyans, yatay kesit bağımlılığı ve otekorelasyon testleri uygulanmıştır. Yatay kesit bağımlılığı sorunu mevcut olup olmadığını anlamak için Breuch_Pagan LM testi gerçekleştirilmiştir. Testin sonucunda olasılık değeri 0,000 bulunmuştur, bu değer modelde yatay kesit bağımlılığı olduğunu göstermiştir.

Modelde değişen varyans sorunu olup olmadığını anlamak için Modified Wald testi gerçekleştirilmiştir. Testin sonucunda olasılık değeri 0,000 çıkmıştır. Bu sebeple modelde değişen varyans sorunu olduğu sonucuna ulaşılmıştır. Lagrange çarpanı (LM) testi oto korelasyon varlığını sınamak için kullanılmıştır. Test sonuçlarına göre olasılık değeri 0, 0167 çıktığı için otekorelasyon problemi olduğu sonucuna ulaşılmıştır. Sonuç olarak model de değișen varyans, yatay kesit bağımlılığı ve otokorelasyon sorunu olduğu tespit edilmiştir. $\mathrm{Bu}$ nedenle çalışmada değișen varyans, yatay kesit bağımlılı̆̆ı ve otokorelasyon sorunlarına karşı dirençli tahminciler kullanılarak model tahmin sonuçları oluşturulmuştur.

\subsection{Bulgular}

Sabit etkiler modellerinde farklı varyans, otokorelasyon ve birimler arası korelasyonun söz konusu olması durumunda, panel veri regresyonun temel varsayımlarına karşı dirençli tahminciler kullanılarak yeni modeller kurulması gerekmektedir. $\mathrm{Bu}$ nedenle çalışmada değişen varyans, otokorelasyon ve birimler arası korelasyona karşı dirençli tahminciler kullanılmıştır ve sonuçları tablo 5 'de verilmiştir.

Tablodan da görüldüğü gibi çalışma da ele alınan bağımsız değişkenlerden biri olan borç oranı ve kontrol değişkeni olan firma büyüklügünün karlılık oranını istatistiki olarak etkilediği belirlenmiştir.

Borç oranının firma karlılığını negatif yönde etkilediği tespit edilmiştir. Bunun yanında firma büyüklügünün ise firma karlılığını pozitif yönde etkilediği bulunmuştur. Modelde ki ikinci ve üçüncü bağımsız değișkenler olan uzun vadeli yabancı kaynak oranı ve kredi riskinin firma karlılığını istatistiki olarak etkilediği ispatlanamamıştır.

Tablo 5: Model Tahmin Sonuçları

\begin{tabular}{|c|c|c|c|}
\hline \multicolumn{4}{|c|}{ Bağımlı Değişken: AK } \\
\hline & Katsayı & $\begin{array}{l}\text { Standart } \\
\text { hata } \\
\text { değeri }\end{array}$ & $p$-değeri \\
\hline Sabit & $\begin{array}{l}- \\
0.1756333\end{array}$ & 0,0283967 & $0,000 *$ \\
\hline Borç & $\begin{array}{l}- \\
0,1188775\end{array}$ & 0,0384062 & $0,002 *$ \\
\hline $\begin{array}{l}\text { Uzun vadeli } \\
\text { borç }\end{array}$ & $\begin{array}{l}- \\
0,0164602\end{array}$ & 0,0283418 & 0,561 \\
\hline Kredi Riski & 0,0077657 & 0,008906 & 0,383 \\
\hline Büyüklük & 0,0295535 & 0,0034321 & $0,000 *$ \\
\hline
\end{tabular}

(Not: * işareti \%99 güven düzeyinde anlamlı olduğunu ifade etmektedir)

Çalışma da firmaların borç kullanma oranı arttığında firma karlılığının azaldığ bulunmuştur. Çıkan sonuç daha önce yapılan Jouida (2017) , Kaplan, Karadeniz (2016), Hassan (2015), ve Shubita, Alsawalhah (2012) 'in yaptıkları çalışmaların sonuçları ile uyumluluk göstermektedir.

Çalışmada firma büyüklüğünün artmasının firma karlılığını da arttırdığı sonucu bulunmuştur. Çlkan bu sonuç İskenderoğlu, Karadeniz, Atioğlu (2012)'nun yaptıkları çalışmada bulunan sonuç ile uyumluluk göstermektedir. Firma büyüklügüundeki artışın karlılı̆̆ arttırması, firmaların ölçek ekonomisinden yararlanma etkisi ile açıklanabilir.

Çalışmanın sonucunda firma karlılığı ile kredi riski ve uzun vadeli yabancı kaynak oranı arasındaki ilişki istatistiki olarak anlamsız çıkmıştır.

\section{SONUÇ VE ÖNERÍLER}

Firmaların sermaye yapısının firmaların karlılığına etkisi olup olmadığı konusu uzun süredir araştırılmaktadır. Daha önce yapılan çalışmaların sonuçları farklılık göstermektedir bu nedenle sermaye yapısı ve 
firma karlılığı arasındaki ilişki hala araştırılmaya devam etmektedir.

$\mathrm{Bu}$ çalışmada hala tartışılmaya devam edilmekte olan sermaye yapısı kararlarının firma karlılığı üzerinde bir etkisinin olup olmadığı araștırılmıștır. Ayrıca çalışmada firmaların kredi risk düzeylerinin sermaye yapısı ve firma karlılığı arasındaki ilişkide bir farklılık yaratıp yaratmadığı değerlendirilmiştir. $\mathrm{Bu}$ amaçla araştırmanın örneklemini Türkiye'de faaliyet gösteren 235 halka açık firma oluşturmuştur.

Çalışmanın modelinde aktif karlılığı bağımlı değişken, borç oranı, toplam kaynaklar içindeki uzun vadeli yabancı kaynak oranı ve kredi risk düzeyi bağımsız değişkenler ve firma büyüklüğü kontrol değişkeni olarak belirlenmiştir.

Yapılan analizler sonucunda firmaların borç oranının firma karlılığını istatistiki olarak negatif etkilediği bulunmuştur. Firmalarda sermaye yapısı içerisinde borç oranının artması ile firma karlılığı azalmaktadır. Ayrıca, firma büyüklügü ile firma karlılığı arasında pozitif bir ilişki bulunmuştur. Firmaların büyüyerek ölçek ekonomisinden yararlanabildiği ve böylece firma büyüklügünün artmasının firma karlılığına olumlu katkısı olduğu söylenebilir. Son olarak firmaların risk düzeylerinin sermaye yapısı ve karlılık arasındaki ilişki üzerinde bir farklılık yaratmadığı sonucuna ulaşılmıştır.

Borçluluk oranı firmaların karlılığını düşürmektedir. Firma performansını iyileştirmek isteyen finans yöneticilerinin borçluluk oranını azaltması faydalı olacaktır.

Çalışmada borçluluk oranı ve firma karlılığı arasında negatif bir ilişkinin bulunması gelişmekte olan ekonomilerde çıkan sonuçlara benzer bir sonuçtur. Çalışmanın sonucu, gelişmiş ülke örneklemi üzerinde geliştirilen ve borçluluk oranı ile firma karlılığı arasında pozitif ilişki olduğunu savunan geleneksel teorilerin Türkiye gibi gelişmekte olan ülkelere uyarlanırken dikkatli incelenmesi ve değerlendirilmesi gerekliliğini göstermiștir.
Çalışmada borçluluk düzeyi ve firma karlılığı arasında negatif ilişkinin bulunması birkaç nedenle açıklanabilir. Türkiye gibi gelişmekte olan ülkelerde finans piyasası bankacılık sektörünün hâkimiyeti altındadır. Bunun sonucu olarak firmalar çoğunlukla kısa vadeli yabancı kaynak kullanmaktadır. Kısa vadeli yabancı kaynak kullanımı firmaların re finansman sıkıntısı yaşamasına neden olabilmekte ve bu durum firma karlılığını olumsuz etkileyebilmektedir. Ayrıca uzun vadeli finansman imkânının az olması firmaların uzun vadeli yatırım yapma imkânını azaltmakta bu durum da firmaların daha karlı yatırımları kaçırmasına neden olabilmektedir.

İkinci neden olarak, Türkiye'deki faiz oranlarının diğer ülkelere nazaran yüksek olması gösterilebilir. Özellikle 2014 yılında bir önceki yıla göre faiz oranları 2 katına çıkmıştır. Faiz oranlarının yüksek olması nedeniyle faiz ödemeleri Türk firmalarına büyük yük olușturmaktadır. Yüksek faiz ödemeleri firmaların nakit akışını olumsuz etkilemekte ve hatta daha karl yatırımlara ayırılacak fon miktarını azaltmaktadır.

Üçüncü olarak McConell ve Servaes (1995) hızlı büyüyen firmalarda borçlanmanın firma performansını olumsuz etkilediği sonucuna ulaşmıştır. Yüksek büyüme oranlarına sahip ülkelerde hızlı büyüyen firmalara daha çok rastlanmaktadır (Wu ve Yue, 2009). Türkiye'de 2013-2017 döneminde ortalama \%6,08 büyürken bu dönemde dünya büyüme ortalaması \%2,77 olarak gerçekleşmiştir. Türkiye'de yüksek büyüme oranlarına sahip bir ülkedir, dolayısıyla sermaye yapısı ve firma karlılığı arasında negatif bir ilişkinin mevcut olması beklenen bir sonuçtur.

Son olarak Türkiye gibi gelişmekte olan ülkelerin uluslararası piyasalardan dış kaynak bulma imkânı kısıtlıdır. Bu nedenle firmalar esas olarak banka kredilerine bağımlı kalmaktadır. Uluslararası piyasadan daha uygun maliyetli kaynaklara erişimin kısıtlı olması firmaların uzun vadeli karlı yatırım 
alternatiflerini kaçırmalarına neden olabilmektedir.

Çalışmada veri kısıtı nedeniyle çalışma sadece Türkiye örnekleminde uygulanmıștır. İleriki çalışmalarda örneklem genişletilerek tüm gelişmekte olan ülkelere uygulanması yararlı olacaktır.

Son olarak kredi derecelendirme gibi firmaların kredi risk düzeyleri ile ilgili bilgilerin mevcut olmaması nedeni ile çalışmada kredi riski için firmaların borçluluk düzeyine bağlı olarak bir değerlendirme yapılmıştır. $\mathrm{Bu}$ nedenle kredi riski değişkeninin açıklayıcılığı kısıtlıdır. İleriki çalışmalarda kredi derecelendirme gibi kriterlerin dahil edilerek kredi riskinin ölçülmesi ile kredi riski değişkeni daha açıklayıcı hale gelebilir.

\section{REFERANSLAR}

Abor, J., (2005), 'The Effect of Capital Structure on Profitability: An Empirical Analysis of Listed Firms in Ghana', The Journal of Risk Finance, Vol. 6 No. 5.

Akgüneș, A. 0., (2017), 'Sermaye Yapısının Karlılığa Olan Etkisinin Panel Veri Analizi Yöntemi İle İncelenmesi: Bıst Bilişim Endeksinde Bulunan Firmalar Üzerine Bir Uygulama', Akademik Sosyal Araștırmalar Dergisi, Yll: 5, Sayı: 62, Aralık 2017, s. 429-438.

Akkaya, G.C., (2008), 'Sermaye Yapısı, Varlık Verimliliğgi Ve Kârlılık: İmkb'de Faaliyet Gösteren Deri-Tekstil Sektörü İșletmeleri Üzerine Bir Uygulama', Erciyes Üniversitesi İktisadi ve İdari Bilimler Fakültesi Dergisi, Sayı: 30, Ocak-Haziran 2008, ss.1-13.

Akerlof, G. (1970), 'The Market For Lemons: Quality Uncertainity and the Market Mechanism' , The Quarterly Journal of Economics, 84 (3), 488 - 501.

Alsu, E., (2017), 'Sermaye Yapısının Kârlılık Üzerindeki Etkisi: BIST 100 Üzerine Panel Veri Analizi', Gaziantep University Journal of Social Sciences, 16 (2), 303-312.

Andaleeb, S. \& M.A. Abbasi \& S.I.H. Naqvi \& S. Ali (2018), "Determinants of Capital Structure of Leasing Companies in Pakistan", Archives of Business Research, 6(3), 104-119

Asteriou, D. \& Hall, S. G., (2011), 'Applied Econometrics' 2nd Edition, New York: Palgrave Macmillan.
Azhagaiah, R. ve Gavoury C., (2011), 'The Impact of Capital Structure on Profitability with Special Reference to it Industry in India', Managing Global Transitions 9 (4): 371-392.

Bos, T. ve Fetherston, T.A., (1993), 'Capital Structure Practices on the Pacificrim', Research in International Business and Finance, Vol. 10, pp. 53-66.

Brealy, R. A. Ve Myers, S. C., (1991), 'Principles of Corporate Finance', 4th Edition, McGraw-Hill Inc., USA.

Brealey R. A., Myers, S. C. ve Alan, J. M., (2007), 'İşletme Finansının Temelleri', (Çev.: Ünal Bozkurt, Türkan Arıkan ve Hatice Doğukanlı), Beşinci Basım, Literatür Yayıncıllk, İstanbul.

Çoşkun A., Güngör B., (2015), 'Sermaye Yapısını Etkileyen Faktörler: Panel Veri Analizi ile Bist Sinai Sektörü Üzerine Bir Uygulama', Atatürk Üniversitesi Sosyal Bilimler Enstitüsü Dergisi 201519 (3): 337 356.

Doğan, M., (2013), 'Sigorta Firmalarının Sermaye Yapısı İle Karlılık Arasındaki İlişki: Türk Sermaye Piyasası Üzerine Bir İnceleme' , Muhasebe ve Finansman Dergisi Ocak/2013.

Durand, D., (1952), 'The Cost of Debt and Equity Funds For Business: Trends And Problems of Measurement, Conference on Research on Business Finance', New York National Bureau of Economic Research, s. 215262. 


\section{F. KÜÇÜKBAY - B. GÜLER}

Fama, E. ve French, R. (1998), 'Taxes, Financing Decisions and Firm Value', The Journal of Finance, Volume: 53, Issue: 3, s. 820821.

Gill, A., Biger N., Mathur N., (2011), 'The effect of capital structure on profitability: Evidence from the United States'. International Journal of Management, Vol. 28, No. 4, Part 1, pp. 3-15.

Gülșen, A. Z. ve Ülkütaş, Ö., (2012), 'Sermaye Yapısının Belirlenmesinde Finansman Hiyerarşisi Teorisi ve Ödünleşme Teorisi: İMKB Sanayi Endeksinde Yer Alan Firmalar Üzerine Bir Uygulama',Uluslararası Yönetim İktisat ve İşletme Dergisi,8(15), 4959.

Hamid, A. M., Abdullah, A., Kamaruzzaman, N. A., (2015), 'Capital Structure and Profitability in Family and NonFamily Firms: Malaysian Evidence' , Procedia Economics and Finance 31 ( 2015 ) 44-55.

Hassan, M. A., (2015), 'Sermaye Yapısı Ve Karlılığa Etkisi: Gıda Firmaları Üzerine Bir Çalışma', Eskișehir Osmangazi Üniversitesi Yüksek Lisans Tezi

İskenderoğlu, Ö., Karadeniz, E., Atioğlu, E., (2012), 'Türk Bankacılık Sektöründe Büyüme, Büyüklük ve Sermaye Yapısı Kararlarının Karlılığa Etkisinin Analizi' , Eskişehir Osmangazi Üniversitesi İibf Dergisi, Nisan 2012, 7(1), 291-311.

Jensen, M. ve Meckling, H. W., (1976), 'Theory of The Firm: Managerial Behavior, Agency Costs and Ownership Structure', Journal of Financial Economics, Volume: 3, Issue: 4, s. 305-360.

Jouida, S., (2017), 'Diversification, capital structure and profitability: A panel VAR approach', Research in International Business and Finance.

Kabakçı, Y., (2008), 'Sermaye Yapısı İle İşletme Performansı Arasındaki İlişki: Gıda Sektöründe Bir Uygulama', Ege Akademik Bakış / Ege Academic Review 8(1) 2008: 167 182.
Kaplan, F., Karadeniz, E., Günay, F., (2016), 'Sermaye Yapısı Kararlarının Kârlılığa Etkisi: Borsa İstanbul Turizm Şirketlerinde Bir Araştırma' , Seyahat ve Otel İşletmeciliği Dergisi/ Journal of Travel and Hospitality Management 13 (3), 2016, 38-55.

Lara, J. E., Mesquita, J. M. C., (2015), 'Capital Structure And Profitabllity: The Brazılian Case'.

Le, T. P. Vy, Phan, T. B. N. (2017), 'Capital structure and firm performance: Empirical evidence from a small transition country', Research in International Business and Finance, 42, 710-726

Li Kang, Niskanen Jyrki, Niskanen Mervi, (2019) 'Capital structure and firm performance in European SMEs: Does credit risk make a difference?', Managerial Finance $45(4)$

McConnel, J. J., Servaes H., (1995) ‘ Equity ownership and the two faces of debt', Journal of Financial Economics, 39(1)

Miller, M., (1977), 'Debt And Taxes', The Journal of Finance, Volume: 32, Issue: 2, s. 261275.

Milton, H. ve Raviv, A. (1991), 'The Theory of Capital Structure', The Journal of Finance, Volume: 46, Issue:1, s. 297-355.

Modigliani, F. and Miller, M., (1958), 'The Cost of Capital, Corporate Finance and the Theory of Investment', American Economic Review, Vol. 48, pp. 261-97.

Modigliani, F. and M. Miller., (1963), 'Corporate income taxes and the cost of capital: A correction'. American Economic Review, Vol.53, pp. 433-53.

Mohammadzadeh, M., Rahimi, F., Rahimi, F., Aarabi, M. J., Salamzadeh, J., (2013), 'The Effect of Capital Structure on the Profitability of Pharmaceutical Companies The Case of Iran' , Iranian Journal of Pharmaceutical Research, 12 (3): 573-577 Received: Jun 2013 Accepted: July 2013. 
Myers, S.C., (2001), 'Capital Structure', Journal of Economic Perspectives Volume 15, Number 2-Spring 2001-Pages 81-102.

Myers S.C., (1977), 'Determinants of corporate borrowing', Journal of Financial Economics, 1977; 5: 147- 76.

Myers, S. C. ve Majluf, N. S., (1984), 'Corporate Financing and Investment Decision When Firms Have Information That Investors Do Not Have', Journal of Financial Economics, Volume: 13, Issue: 2.

Noe, Thomas H. (1988), 'Capital Structure and Signaling Game Equilibria', Review of Financial Studies, Volume: 1, Issue: 4.

Ross, Stephen A. (1977), 'The Determination of Financial Structure: The Incentive- Signalling Approach', The Bell Journal of Economics, Volume: 8, Issue: 1, s. 23-40.

Sayılgan G., (2017), 'Soru ve Yanitlarıyla İşletme Finansmanı', Siyasal Kitapevi, Ankara

Shubita, M. and Alsawalhah, J., (2012), 'The Relationship between Capital Structure and Profitability', International Journal of Business and Social Science Vol. 3 No. 16 [Special Issue - August 2012].

Söylemez, Yakup (2019), 'Firmaların Sermaye Yapısını Etkileyen Faktörler: Demir Çelik Metal Ana Sanayi Uygulaması, Sosyoekonomi', 27(40)

Topal, Y., (2006), 'İmkb’ye Kayıtlı İşletmelerin Sermaye Yapıları Ve Finansal Kaldıraç Oranlarının Karlılıklarına Etkisi', Erciyes Üniversitesi İktisadi ve İdari Bilimler Fakültesi Dergisi, Sayı: 27, Temmuz-Aralık 2006, ss. 45-70.

Thomson Reuters Eikon. (2018). https://eikon.thomsonreuters.com/(Accesse d Date: 01.07.2018)

Wu, L \& Yue, H 2009 'Corporate Tax, Capital Structure, and the Accessibility of Bank Loans: Evidence from China', Journal of Banking \& Finance, vol.33, pp30-38.

Yakar , R., (2011), 'Sermaye Yapısı Teorileri Ve İmkb' De Ampirik Bir Çalışma', Selçuk Üniversitesi Yüksek Lisans Tezi 